\title{
Esofagoplastia torácica com retalho de pericárdio em gatos
}

\author{
Thoracic esophagoplasty with pericardial flap in cats
}

\author{
Olices da Cunha ${ }^{1}$ Ney Luis Pippi ${ }^{2}$ Alceu Gaspar Raiser ${ }^{2}$ Saulo Tadeu Lemos \\ Pinto Filho $^{3}$ Luz Guaimás Moya ${ }^{3}$ Leandro Haczkiewicz Gaiga ${ }^{3}$ Marilda \\ Onghero Taffarel ${ }^{4}$ Alexandre Rios ${ }^{4}$ Danieli Rankel Fernandes ${ }^{4}$
}

\section{RESUMO}

Com o objetivo de testar a eficiência do retalho de pericárdio autógeno pediculado como alternativa para reparar defeitos esofágicos torácicos em felinos, foram estudados doze animais adultos, sendo seis avaliados até 15 dias e os outros seis até 30 dias de pós-operatório. Todos os animais foram submetidos à ressecção esofágica e posterior reparo com pericárdio pediculado. As análises constaram de exames clínicos diários e, ao final do período estabelecido, os animais foram submetidos à eutanásia e necropsiados para avaliação macroscópica e microscópica dos esôfagos. Observou-se proliferação da mucosa esofágica sobre o pericárdio pediculado.

Palavras-chave: pericárdio, esôfago, felinos, esofagoplastia, pedículo.

\section{ABSTRACT}

The efficiency of autogenous pericardial flap was evaluated as an alternative surgical procedure for repairing lesion in the thoracic esophagus in the feline. Twelve adult cats were studied. Six animals were observed at the $15^{\text {th }}$ day and other animals at the $30^{\text {th }}$ day. All animals were submitted to esophageal resection and subsequently repair with autogenous pericardial graft. The animals were clinically evaluated after surgery. At the determined period of observation the animals were sacrificed. Gross and microscopic evaluation were done from the surgical site at the esopahagus. An esophageal mucous membrane proliferation was identified on most of the grafts.

Key words: pericardium, esophagus, feline, esophagoplasty, flap.

\section{INTRODUÇÃO}

O esôfago é um órgão predisposto a lesões capazes de produzir consideráveis perdas teciduais. É relatado que rupturas, lacerações e perfurações são causadas por grande diversidade de corpos estranhos (FREEMAN, 1982), projéteis balísticos, objetos perfurantes (HOFMEYER, 1974) e ingestão acidental de agentes químicos corrosivos (CORSI et al., 2000), podendo ocasionar úlcera necrótica.

Estenoses esofágicas, neoplasias, como carcinoma epidermóide ou sarcomas (SCHIRMER et al., 1997), traumatismos, granulomas causados por Spirocerca lupi, esofagite ulcerativa severa, divertículo ou dilatação podem requerer reconstrução esofágica em cães (STRAW et al., 1987). A maior incidência de perfuração esofágica decorrente de traumas internos

${ }^{1}$ Médico Veterinário, Aluno do Programa de Pós-graduação em Medicina Veterinária da Universidade Federal de Santa Maria (UFSM), Docente do Curso de Medicina Veterinária da Universidade Federal do Paraná, Campus Palotina (UFPR). Rua Pioneiro, 2153, 85950-000, Palotina, PR E-mail:olicies@bol.com.br. Autor para correspondência.

${ }^{2}$ Médico Veterinário, Professor titular, Doutor, Docente do Departamento de Clínica de Pequenos Animais, UFSM.

${ }^{3}$ Médico Veterinário, Mestrando do PPGMV/UFSM.

${ }^{4}$ Aluno de Graduação, do Curso de Medicina Veterinária (UFPR). 
ocorre no segmento torácico, devido a corpos estranhos, sondas, produtos químicos e doenças inflamatórias (BORBA JÚNIOR et al., 1998).

A falta de um revestimento seroso, vascularização sanguínea segmentar, movimentação, ausência de distensão longitudinal, são fatores que aumentam os índices de complicações cirúrgicas neste órgão (PARKER \& BROCKINGTON, 1949; PAVLETIC, 1996). A cirurgia esofágica é mais sensível à deiscência e extravasamento que outras porções do aparelho digestório (PAVLETIC, 1996).

Segundo WALDRON (1991), as lesões esofágicas com menos de um quarto da circunferência esofágica e que tenham bordas de tecido viável, podem ser debridadas e suturadas. Nas lesões maiores, são necessários procedimentos alternativos para substituir segmentos esofágicos (DALECK et al., 1988), pois suturas apenas podem levar à deiscência ou estenose (BORBA JÚNIOR et al., 1998).

Esofagectomia com anastomose ou substituição do tecido esofágico danificado por retalho, enxerto ou prótese, tubos de pele, produção de tubo gástrico, são alternativas citadas pela literatura, porém, em muitos casos há necessidade de abordagem tóraco-abdominal combinada ou dois tempos cirúrgicos (CORAN, 1973; STRAW et al., 1987; CONTESINI, 1992; PIGATTO et al., 1998; FREITAS et al., 2000).

CORAN (1973) usou, experimentalmente, pericárdio pediculado para reparar defeitos esofágicos torácicos em caninos obtendo resultados satisfatórios, com proliferação da mucosa sobre o leito pericárdico. Os músculos esternomastóideo e cleidomastóideo como forma de retalho, foram utilizados por CONTESINI et al. (1992), os quais constataram que são boas alternativas para lesões esofágicas cervicais, pois, além do procedimento cirúrgico ser facilitado pela localização e apresentação anatômica, a vascularização muscular favorece a regeneração epitelial. BORBA JÚNIOR et al. (1998) usaram para reparar defeitos esofágicos cervicais em cães, fáscia lata autógena. Observaram alto índice de estenose e fístulas, desaconselhando este procedimento para corrigir ferimentos penetrantes do esôfago.

BARCELLOS (1999) usou três tipos de vias de administração de dietas pós-operatórias em cães submetidos à esofagotomia cervical. Observou que o uso de sonda gástrica, colocada por gastrostomia endoscópica percutânea, resultou em cicatrização mais rápida e de melhor qualidade, quando comparada à sonda faringo-gástrica e fluidoterapia por 48 horas, seguida de dieta líquida e pastosa. ZILBERSTEIN et al. (1987) relataram que, após procedimentos cirúrgicos esofágicos, a alimentação deve ser a mais natural possível e recomendam evitar maior mutilação ao tecido corpóreo para estabelecer sondas alimentares.

A estenose esofágica pós-operatória pode ser avaliada por radiografias contrastadas ou no exame pós-morte, com alginato injetado no esôfago, sendo depois aferidas suas medidas. $\mathrm{O}$ uso do alginato mostra o relevo interno do esôfago (BORBA JÚNIOR et al., 1998). O tempo de avaliação de cirurgias esofágicas pode variar com os propósitos e com o tipo de cirurgia, sendo que PRIMO (1955) relata o tempo de 30 dias por haver poucas complicações após este período.

A proposta deste estudo foi testar a eficiência do pericárdio autógeno pediculado para reparar defeitos esofágicos torácicos produzidos em gatos, avaliando-se o grau de estenose pós-operatória, as alterações no comportamento alimentar, o pericárdio como leito para proliferação epitelial e a eficiência da dieta alimentar proposta.

\section{MATERIAL E MÉTODOS}

Foram estudados doze gatos adultos, machos e fêmeas, sem raça definida, submetidos a exame físico, e na sequiência, alojados em gaiolas por um período de 15 dias para adaptação, onde receberam alimentação e manejo adequados. Seis animais foram avaliados até 15 dias e os demais até 30 dias de pósoperatório.

Para terapia antimicrobiana profilática, foi utilizada ampicilina sódica, na dose de $20 \mathrm{mg} / \mathrm{kg}$ pela via intravenosa, imediatamente antes da indução anestésica, que foi feita com cloridrato de xilazina $2 \% \mathrm{e}$ cetamina na dose de $1 \mathrm{mg} / \mathrm{kg}$ e $10 \mathrm{mg} / \mathrm{kg}$, respectivamente, ambos por via intramuscular. A anestesia foi mantida com halotano em vaporização com oxigênio. Com o animal devidamente anestesiado e contido em decúbito lateral esquerdo, foi procedida abordagem torácica no $4^{\circ}$ espaço intercostal direito. $\mathrm{O}$ esôfago foi localizado com auxílio de sonda esofágica e exposto através de dissecção romba do tecido circundante. Na seqüência, foi preparado um retalho de pericárdio após a liberação do nervo frênico e preservação dos vasos sanguíneos, seguido de produção do defeito no esôfago com $0,5 \times 1,0 \mathrm{~cm}$. O retalho foi suturado sobre o defeito com poliglactina 910, n. 4.0 a 6.0, dependendo do tamanho do animal, usando sutura em "U" de aposição látero-lateral (KNECAT et al., 1985).

A síntese da parede torácica foi realizada de maneira rotineira e a terapia antiálgica foi procedida com cetoprofeno na dose de $2 \mathrm{mg} / \mathrm{kg}$, intravenoso, logo ao término da cirurgia e $1 \mathrm{mg} / \mathrm{kg}$ subcutâneo a cada 24 horas durante mais quatro dias. 
O jejum foi mantido por 24 horas após a cirurgia. Durante este período, os animais receberam fluidoterapia com solução de Ringer com lactato na dose de $100 \mathrm{ml} / \mathrm{kg} / \mathrm{dia}$, dividida em duas vezes ao dia. Do $2^{\circ}$ ao 5 o dia de pós-operatório, receberam dieta líquida com consistência gradativamente aumentada, constituída de leite, ração líquida e água ad libitum. Do $6^{\circ}$ ao $8^{\circ}$ dia receberam dieta pastosa constituída de ração comercial umedecida com água. A partir de então, foram alimentados com ração comercial sólida.

Exames clínicos diários foram realizados até o sétimo dia de pós-operatório, constando de avaliação do estado físico, atitude à alimentação, padrão respiratório e temperatura retal.

A eutanásia foi realizada em seis animais aos 15 dias de pós-operatório e, nos outros seis, aos 30 dias de pós-operatório, utilizando-se acepromazina, tiopental e cloreto de potássio. À necropsia, o enxerto foi analisado quanto à presença de aderências, fístulas, deiscências e estreitamentos no diâmetro. $\mathrm{O}$ esôfago foi isolado numa extensão de $10 \mathrm{~cm}$, sendo seccionadas suas extremidades junto com uma porção do pericárdio. A peça retirada foi deixada sobre gaze embebida com solução fisiológica a $0,9 \%$.

\section{Índice de estenose}

Com a peça operatória em superfície rígida na posição horizontal, procedeu-se a moldagem intraesofágica, com auxílio de uma seringa de $20 \mathrm{ml}$ e solução de hidrocolóide irreversível, denominado Alginato, que é um pó que se torna gelatinoso quando misturado à água. O parâmetro para esta análise foi a medida, em centímetros, do diâmetro do molde do esôfago, no local da aplicação do enxerto, mais o valor do diâmetro medido distando da plastia do esôfago, $2 \mathrm{~cm}$ no sentido cranial e $2 \mathrm{~cm}$ no sentido caudal. Os valores encontrados foram aplicados na fórmula para determinação do índice de estenose, descrito por McADAMS, et al. (1970), que consiste no seguinte:

Índice de estenose $=100\left(1-\frac{2 A}{B+C}\right)$

$\mathrm{A}=$ diâmetro no local do reparo; $\mathrm{B}=$ diâmetro distante $2 \mathrm{~cm}$, cranialmente ao reparo, e $\mathrm{C}=$ diâmetro distante 2 $\mathrm{cm}$, caudalmente ao reparo.

$\mathrm{O}$ índice de estenose zero corresponde à ausência de estenose e o índice 100 é indicativo de estenose total.

\section{Exame da superfície interna da peça cirúrgica}

A peça operatória foi aberta pelo lado oposto ao do procedimento, para ser pesquisada a presença ou não de fístulas, necroses, granulomas e áreas de epitelização da mucosa (Figura 1).

\section{Exame histológico}

Cada peça aberta foi fixada em solução aquosa de formol a $10 \%$ e os fragmentos retirados da região operada foram inclusos em parafina, cortados em micrótomo, corados pelo método HematoxilinaEosina e analisados em microscopia óptica.

\section{RESULTADOS}

O acesso cirúrgico pelo quarto espaço intercostal direito foi adequado para o procedimento,

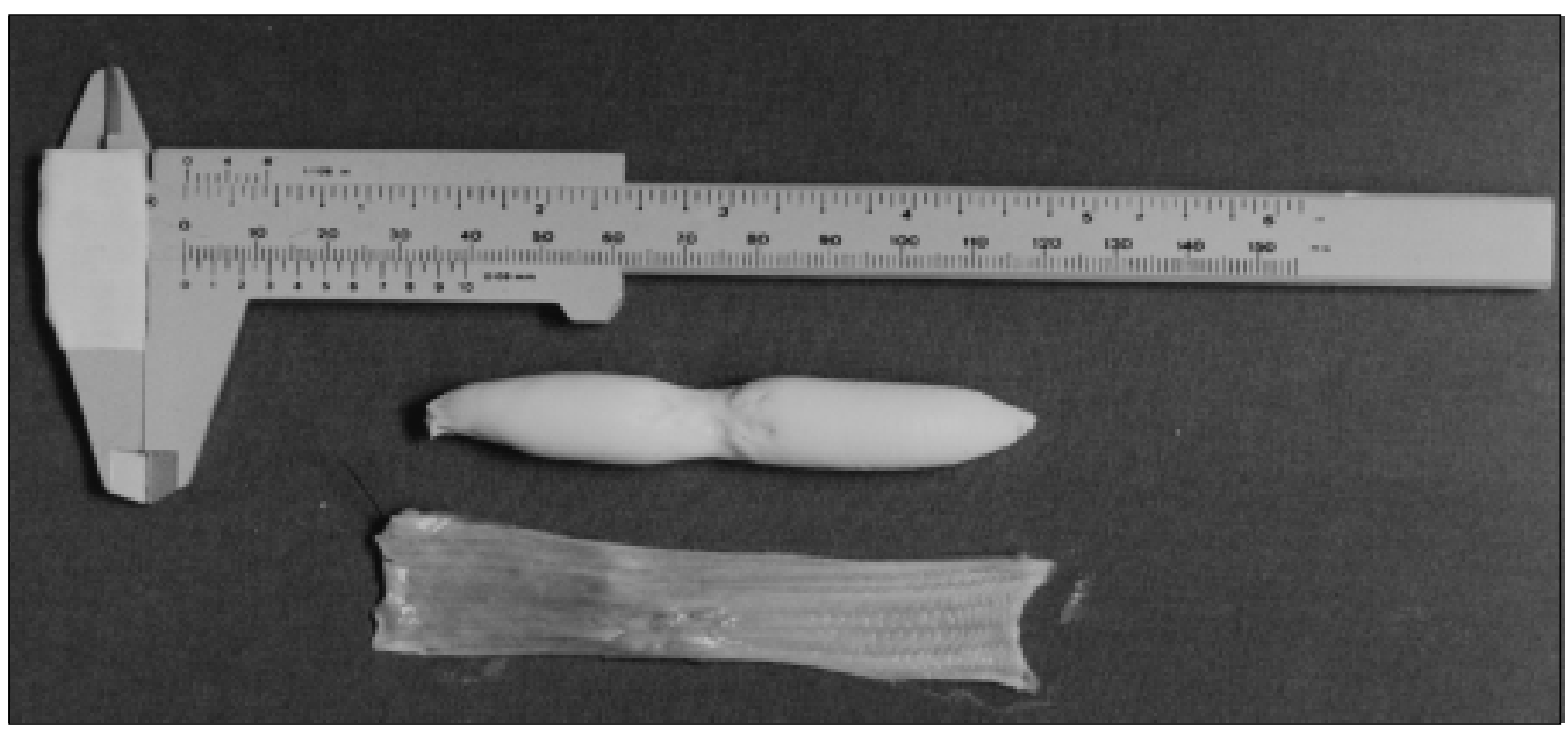

Figura 1 - Paquímetro, molde de alginato e superfície interna esofágica. 
não apresentando dificuldades para manipulação dos tecidos. Foi observada recuperação confortável em nove animais, que apresentaram boa adaptação à alimentação, não sendo observado vômito, regurgitação, tosse, disfagia, e perda de peso no período avaliado. Em dois animais, que foram observados até 15 dias de pós-operatório, houve perda de peso, desconforto respiratório e hiporexia até o momento da eutanásia. Em apenas um animal, avaliado até os 30 dias de pós-operatório, notou-se regurgitação após a alimentação, na transição da dieta pastosa para sólida, que não persistiu além de três dias. À necropsia, foram observadas as seguintes alterações:

Animais avaliados até os 15 dias:

Animal 1: observou-se, à necropsia, presença de piotórax, aderências do pericárdio com pulmão e pleura. Não foram observadas fístulas, deiscência ou estenose na área do enxerto, porém, no pericárdio, havia supuração e aderência. Na superfície interna, foram encontrados pequenos granulomas e epitelização completa.

Animal 2: havia aderência do lobo cranial do pulmão direito com a 5a costela, pericárdio e nervo frênico. Não foi observada fístula ou deiscência, porém havia estenose, presença de um granuloma central de aproximadamente $4 \mathrm{~mm}$ e epitelização visível.

Animal 3: notou-se presença de piotórax e aderência do pulmão com pericárdio, havia fístula, granulomas, necrose e estenose. Não foi observada área de epitelização.

Animal 4: encontrou-se aderência do pulmão com a parede costal e o coração, ocorreu fístula, porém o pulmão estava aderido sobre a fístula e não havia extravasamento para a cavidade. Não foram observadas áreas de epitelização.

Animais 5 e 6: exibiram aderências do lobo pulmonar cranial com a parede costal e esôfago. No animal 5 ainda foi notada a presença de um granuloma, com cerca de $1 \mathrm{~mm}$ na superfície interna do esôfago na região da plastia. Ambos exibiam epitelização.

Animais avaliados até os 30 dias:

Animais 7 e 8: apresentaram aderências do pericárdio com o lobo pulmonar cranial. No 7, notou-se epitelização e estreitamento esofágico no local do reparo e, no animal de número 8 , não foi possível observar estreitamento esofágico, porém foi notado pequeno granuloma ( $2 \mathrm{~mm}$ ) na região da plastia e epitelização completa.

Animais 9, 10, 11 e 12: foram observadas aderências do pulmão com a parede costal, e sobre o leito, havia evidências de proliferação epitelial. No animal de número 10 , havia um pequeno granuloma, de 1 mm, no local do reparo. Os índices de estenose estão sumarizados na tabela 1 .

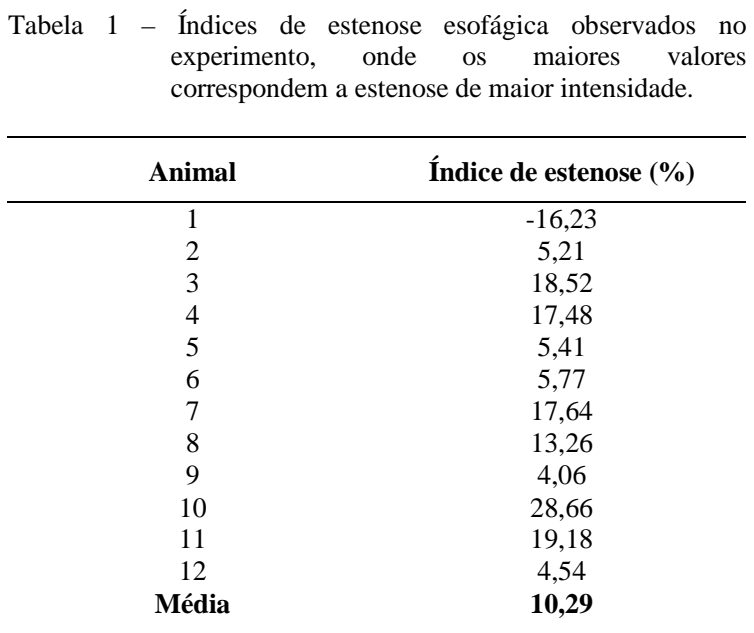

A análise histológica revelou regeneração do epitélio esofágico sobre o leito pericárdico, à exceção dos animais de número 3 e 4, não havendo variação nos dois períodos analisados (Figura 2).

\section{DISCUSSÃO}

Existem várias formas de reconstrução esofágica, porém poucas têm aplicabilidade para esôfago torácico (STRAW et al., 1987). A aplicação da técnica depende muito da localização e tamanho do defeito esofágico e da experiência do cirurgião. O esôfago torácico apresenta, quando comparado a outras porções deste órgão, maior potencial de complicação cirúrgica (BORBA JÚNIOR et al., 1998).

$\mathrm{O}$ acesso pelo quarto espaço intercostal direito proporcionou abordagem adequada ao coração e

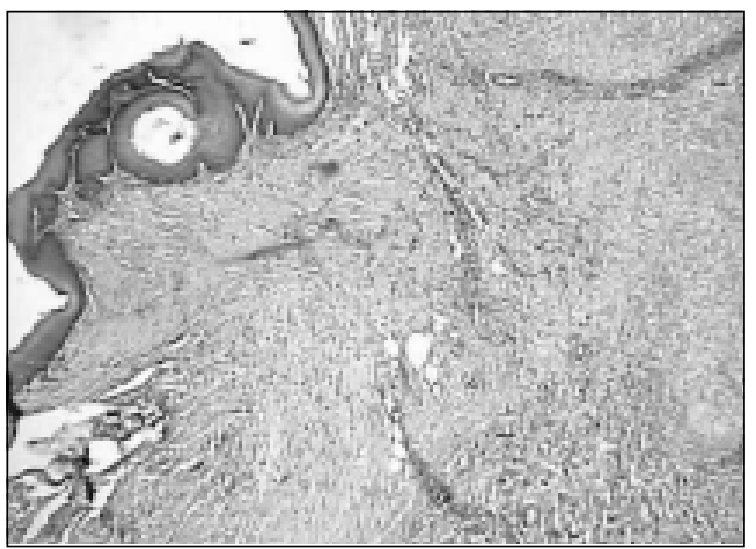

Figura 2 - Aspecto microscópico do esôfago reparado com retalho de pericárdio aos 30 dias, denotando regeneração epitelial sobre o leito pericárdico. 
esôfago. Não foi necessária ressecção de costelas e nem ligadura da veia ázigos para executar a técnica proposta, diferente da técnica utilizada por CORAN (1973), o que tornou o procedimento menos traumático. A dissecção do esôfago e a produção do retalho de pericárdio não apresentaram dificuldade, sendo produzido estrategicamente, com os vasos orientados em paralelo ao eixo maior do retalho, para permitir uma melhor vascularização sangüínea. O pericárdio pediculado apresenta como vantagens a proximidade do esôfago, irrigação preservada e resistência mecânica, sendo desta forma, mais eficiente que outras modalidades de enxertos nestas circunstâncias. $\mathrm{O}$ defeito esofágico foi superior a um quarto da circunferência, suficiente para produzir estenose clinicamente quando, suturado por primeira intenção (WALDRON, 1991).

A sutura em "U” de aposição latero-lateral utilizada no retalho, permite uma melhor vedação e, na base do pedículo, a sutura foi orientada em direção paralela aos vasos, de forma a não estrangular o pedículo (KNECAT et al., 1985).

A dieta proposta no experimento evitou um procedimento cirúrgico adicional para o estabelecimento de uma sonda alimentar, sendo esta uma forma mais natural de alimentação, concordando com ZILBERSTEIN et al. (1987). Essa foi eficiente, uma vez que em nove animais, dos doze avaliados, não houve alteração no comportamento alimentar e nem perda de peso.

Nos animais com fístulas, é possível que tenha sido exercida tensão exagerada no pedículo pericárdico, por ocasião da cirurgia. Um dos animais com fístula não apresentou sinal clínico, pois o pulmão que estava aderido no local do retalho evitava o extravasamento alimentar. No que apresentou piotórax sem fístula, pode ter ocorrido infecção cirúrgica ou falha na profilaxia antimicrobiana.

A observação aos quinze e trinta dias de pós-operatório justifica-se pelo fato de existirem poucas complicações após este período (PRIMO, 1955). A estenose observada em onze animais, à necropsia, não provocou sinais clínicos de estreitamento esofágico, provavelmente pela grande capacidade de distenção deste órgão. Naquele com "estenose negativa" (animal de número 1), houve abaulamento do retalho, também sem sinais clínicos observados. A regurgitação, que pode ocorrer na transição alimentar, foi transitória, como observada no animal de número 11.

A presença da mucosa no local do retalho deve-se ao fato do pericárdio providenciar um bom leito para proliferação epitelial e servir como barreira mecânica para extravasamentos, até que este processo de reparação se complete.

\section{CONCLUSÕES}

Frente aos resultados obtidos, nas condições deste experimento, é possível concluir que o pericárdio pediculado é eficiente na reparação de defeitos esofágicos torácicos em gatos e serve como leito para proliferação epitelial, constituindo uma boa alternativa para estas afecções. A estenose moderada observada à necropsia não provoca disfagia, não sendo suficiente para alterar o fluxo alimentar e a dieta alimentar proposta no trabalho é segura para este tipo de cirurgia, podendo ser usada para cirurgias esofágicas.

\section{FONTESDE AQUISIÇÃO}

a Ampicilina $500 \mathrm{mg}$, BioChimico. Rio de Janeiro, RJ.

b Coopazine, Coopers. Cotia, SP.

c Ketamin, Cristália. Itapira, SP.

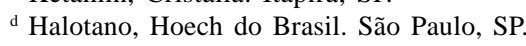

e Vycril, Ethicon. São Paulo, SP.

${ }^{\mathrm{f}}$ Profenid, Rhodia Farma. São Paulo, SP

g Ringer Lactato, Halex-Star. Goiânia, GO.

${ }^{\text {h }}$ Acepran 1\%, Univel. São Paulo, SP.

i Tiopental, Cristália. Itapira, SP.

j Cloreto de Potássio 10\%, Ariston. São Paulo, SP.

k Solução Fisiológia 0,9\%, Halex-Star. Goiânia, GO.

${ }^{1}$ Jeltrate, Dentsply. Petrópolis, RJ.

\section{REFERÊNCIASBIBLIOGRÁFICAS}

BARCELLOS, H.H.A. Influência de três tipos de vias de fornecimento de dietas pós-operatórias em cães submetidos à esofagotomia cervical. 1999. 97f. Dissertação (Mestrado em Medicina Veterinária) - Universidade Federal do Rio Grande do Sul, Porto Alegre.

BORBA JÚNIOR, C.V. et al. Enxerto de fáscia lata autógena em ferimentos penetrantes provocados no esôfago cervical em cães. Acta Cirúrgica Brasileira, São Paulo, v.13, n.3, p.184 $-193,1998$.

CONTESINI, E.A. et al. O uso do músculo esternomastóideo com "flap" na reconstrução parcial da parede esofágica cervical em bovinos. Ciência Rural, Santa Maria, v.22, n.2, p.171$177,1992$.

CORAN, A.G. Pericardioesophagoplasty. A new operation for partial esophageal replacement. The American Journal of Surgery, New York, v.125, p.294-299, 1973.

CORSI, P.R. et al.. Lesão aguda esôfago-gástrica por agente químico. Revista da Associação Médica Brasileira, São Paulo, v.46, n.2, p.98-105, 2000.

DALECK, C.R.; DALECK, C.L.M.; GANDOLFI, W. Esofagoplastia cervical no cão com peritônio autólogo ou homólogo - "estudo experimental". Ciência Veterinária, Jaboticabal, v.2, n.1, p.1-2, 1988.

FREEMAN, D.E. The alimentary system. In: MANSMANN, R.A.; McALLISTER, E.S. Equine medicine and surgery. 
2.ed. Santa Barbara : American Veterinary, 1982. V.1, cap.13, p.437-44.

FREITAS, P.M.C. et al. Reparo de esôfago cervical de cães com implante de segmento intestinal livre, desprovido do epitélio e da lâmina própria da túnica mucosa. In: CONGRESSO BRASILEIRO DE CIRURGIA E ANESTESIOLOGIA VETERINÁRIA, 4., 2000, Goiânia. Anais... Goiânia : UFG, 2000. 296p. p.112.

HOFMEYER, C.F.B. The digestive system: the esophagus. In: OEHME, F.W.; FRIER, J.E. Textbook of large animal surgery. Baltimore : William \& Wilkins, 1974. Cap.11, p. 364-449.

KNECAT, C.D. et al. Técnicas fundamentais em cirurgia veterinária. 2.ed. São Paulo : Rocca, 1985. Cap.3, p 55-56.

McADAMS, A.J.; MEIKLE, A.G.; TAYLOR, J.O. One layer or two layer colonic anastomosis? The American Journal of Surgery, New York, v.120, p.546-50, 1970.

PARKER, E.F.; BROCKINGTON, W.S. Esophageal resection with end-to-end anastomosis: experimental and clinical observations. Annals of Surgery. v.129, p.558-605, 1949.

PAVLETIC, M.M. Esôfago (Técnicas de reconstrução esofágica). In: BOJRAB, M.J. Técnicas atuais em cirurgia de pequenos animais. 3.ed. Roca : São Paulo, 1996. p.192203.
PIGATTO, J. A. et al. Esofagoplastia cervical em caninos com enxerto homólogo de cartilagem conchal preservado em glicerina. Ciência Rural, Santa Maria, v. 28, n.4, p. 617$621,1998$.

PRIMO, G. Observation experimentalles sur la suture oesophagienne essai de suture en un plan. Acta Chirurgica Belgica, v.54, p.772-789, 1955.

SCHIRMER, C.C. et al. Neoplasias associadas ao carcinoma epidermóide do esôfago. Revista da Associação Médica Brasileira, São Paulo, v.43, n.4, p 334-339, 1997.

STRAW, R.C. et al. Use of a vascular skeletal muscle graft for canine esophageal reconstruction. Veterinary Surgery, Philadelphia, v.16, n.2, p.155-163, 1987.

WALDRON, D.R. Ressecções e anastomoses do esôfago cervical e torácico. In: BOJRAB, M.J. Cirurgia dos pequenos animais. 2.ed. São Paulo : Roca, 1991. Cap.11, p.146-154.

ZILBERSTEIN, B. et al. Auto-transplante do intestino delgado em substituição ao esôfago cervical. Indicação, técnica e experiência clínica. Revista do Hospital de Clínicas da Faculdade de Medicina de São Paulo, v. 42, n.1, p.21-25, 1987. 